\title{
Pharmaceutical cost management in an ambulatory setting using a risk adjustment tool
}

\author{
David Vivas-Consuelo ${ }^{1 *}$, Ruth Usó-Talamantes ${ }^{2}$, Natividad Guadalajara-Olmeda', José-Luis Trillo-Mata², \\ Carla Sancho-Mestre ${ }^{1}$ and Laia Buigues-Pastor ${ }^{2}$
}

\begin{abstract}
Background: Pharmaceutical expenditure is undergoing very high growth, and accounts for $30 \%$ of overall healthcare expenditure in Spain. In this paper we present a prediction model for primary health care pharmaceutical expenditure based on Clinical Risk Groups (CRG), a system that classifies individuals into mutually exclusive categories and assigns each person to a severity level if $s /$ he has a chronic health condition. This model may be used to draw up budgets and control health spending.
\end{abstract}

Methods: Descriptive study, cross-sectional. The study used a database of 4,700,000 population, with the following information: age, gender, assigned CRG group, chronic conditions and pharmaceutical expenditure. The predictive model for pharmaceutical expenditure was developed using CRG with 9 core groups and estimated by means of ordinary least squares (OLS). The weights obtained in the regression model were used to establish a case mix system to assign a prospective budget to health districts.

Results: The risk adjustment tool proved to have an acceptable level of prediction $\left(R^{2} \geq 0.55\right)$ to explain pharmaceutical expenditure. Significant differences were observed between the predictive budget using the model developed and real spending in some health districts. For evaluation of pharmaceutical spending of pediatricians, other models have to be established.

Conclusion: The model is a valid tool to implement rational measures of cost containment in pharmaceutical expenditure, though it requires specific weights to adjust and forecast budgets.

Keywords: Risk adjustment, Predictive models, Pharmaceutical expenditure, Chronic condition, Clinical Risk Groups, Capitation payments

\section{Background}

The growth in pharmaceutical cost is a real problem in health care sustainability [1]. This is due to a number of factors: ageing of population, introduction of new medicines and changes in prescription practices and agerelated patient complexity. Furthermore, studies focusing on a clear understanding of pharmaceutical consumption, cost and morbidity patterns are needed to implement effective cost control.

One of the widest used tools for cost control in health expenditure is that of risk adjustment, used to make capitation finance systems. These can be found worldwide for

\footnotetext{
* Correspondence: dvivas@upvnet.upv.es

${ }^{1}$ Research Centre for Health Economics and Management, Universitat Politècnica de València, Edificio 7 J, Campus de Vera s/n, 46022 Valencia, Spain

Full list of author information is available at the end of the article
}

both clinical and pharmaceutical management. In health systems where competition between insurance companies exists, such as USA and Germany, capitation attempts to avoid adverse risk selection. In other countries with comprehensive national health systems, such as UK and Sweden, capitation is used for an equitable distribution of resources [2].

Early approaches to adjustment of health expenditure were based on demographic variables alone. However, the introduction of other clinical variables related with population health statuses has improved this adjustment in several countries.

The work of Mossey and Roos [3] was the starting point for different studies that use disease related cost for risk adjustment, using information from insurance companies. The first diagnostic based models for forecasting health 
expenditure were introduced in the 80s, employing AAPC (Adjusted Average Per Capita Cost) [4] and DCG (Diagnostic Cost Groups) [5].

In the last 20 years, various studies have been carried out on the use of cost indicators based on information available from electronic records previously used by clinical services. The three best known Diagnostic Based Risk Adjustment Systems (DBRAS) are: Diagnostic Cost Groups/Hierarchical Coexisting Conditions (DCG/HCC) developed by Pope et al. [6,7], Adjusted Clinical Groups (ACG) developed by Starfield et al. [8] and Weiner et al. [9] at Johns Hopkins University in Baltimore and Clinical Risk Groups (CRG) developed by Hughes et al. [10]. All of these are based on the International Classification of Disease, 9th Revision, Clinical Modification (ICD-9-CM), the codes of which are recorded electronically. While the DCG is based on cost, ACG and CRG were developed to measure health statuses.

According to a study by Berlinguet, Preyra and Dean [11], the CRG have greater clinical relevance while offering a predictive power similar to the other two systems (ACG and DCG/HCC).

Another important classification system is the Chronic Disease Score (CDS), developed by Von Korff et al. [12] using pharmaceutical consumption to identify chronic conditions of patients. This uses pharmacy databases to estimate disease prevalence in the absence of diagnostic information. Moreover, these databases have the advantage of generally being complete, precise and reliable, while codification of diagnostics may only register those conditions treated during a clinical visit or hospital stay and, as such, not reflect other important chronic conditions [13].

Various later studies have analysed the validity of the four health state indicators above, perfecting them and adapting them to each specific situation. Thus, different models of pharmaceutical expenditure were obtained from the CDS [14-19], DCG/HCC system [20,21].

Although the ACG [22,23], and CRG systems were developed to measure health status, their validity in explaining pharmaceutical expenditure has also been demonstrated [24-26].

In the United States, Medicare uses the developed DCG/ HCC model. In 2006 they implemented the model, CMS (Centres for Medicare and the Medicaid) prescription drug hierarchical condition categories RxHCC [27]. For capitation payments the CMS-HCC model [7], based only on diagnostics, is used. The use of differentiated models for capitation and medicine payments is based on the findings of Zhao et al. [28], who give better predictive power for future prescription drug costs for mixed models that combine diagnostic and drug use data.

Other countries have their own system, such as that in Germany, where a morbidity based risk adjustment was introduced in 2009, embedded in a broader reform of the statutory health insurance system. The new formula covers 80 "severe" or "costly and chronic" diseases structured in a system of hierarchical groups [29].

The CRG system in Spain was first implemented in the Baix Empordà Health Service (Serveis de Salut del BaixEmpordà) [30], and projects are under way in the Autonomous Communities of Catalonia and Madrid. Other Autonomous Communities like the Pais Vasco [31] and some health centres in the Balearics [32] have opted for ACG. Regardless of the system used, all these suppose a significant advance on previous systems based on epidemiological variables [33] or prescriptions [14].

Over recent years, the Valencian Community (VC) (East coast of Spain) has been interested in adapting health expenditure by linking it with population morbidity. Firstly, the General Directorate of Pharmaceutical and Health Products (DGFPS) of the Valencian Health Department designed a standardised amount indicator [34] which offered primary health care pharmaceutical expenditure data per patient covered in a year. This allowed the standardisation of the population based on two categories: patients covered by the health system who have the right to free medication (fundamentally pensioners) and patients covered by the system who must pay part of the cost of the medication from the pharmacy. According to this, in 2011 primary health care pharmaceutical expenditure per standardised patient was 338 Euros, compared with the 275 Euros obtained without standardisation.

This indicator supposes an improvement regarding precision of results and was achieved thanks to the development of appropriate information systems and more specifically that of the primary health care electronic health record [35].

Vivas et al. [36] developed a model using Anatomical Therapeutic Chemical Classification (ATC) from electronic prescriptions drug data to explain pharmaceutical expenditure at a local level.

Since 2010, the DGFPS has been developing a system of patient classification in the VC based on CRGs, which allows stratification of patients according to morbidity. The differences between the use of data from prescriptions and diagnostics that have been observed in the DCG models do not affect the models based on CRG. The predictive power of CRG for future pharmaceutical expenditure has been demonstrated in three prior studies [24-26].

The goal of this work is to obtain a concurrent model of primary health care pharmaceutical expenditure for the entire region using CRGs. From this model we obtain weights for primary health care pharmaceutical expenditure per inhabitant and year based on the CRG, which may then be used to draw up budgets for the following 
year and control health spending in the 24 health districts of VC.

\section{Methods \\ Data}

The data was taken from the Population Information System's (PIS) database of all patients registered and assigned to one of the 24 health districts in the $\mathrm{VC}$, a region of 4.7 million inhabitants for the period $1^{\text {st }}$ Jan to $31^{\text {st }}$ Dec for 2012 and 2013. Although the initial number of patients was 5.2 million, 400,000 were discarded as nonresidents with a stay of less than one month, leaving a total of 4.7 million for analysis. All information was made anonymous according to data protection regulations and our study was approved by the Behavioural Research Ethics Board at the Generalitat Valenciana.

For each patient we obtained the following information. Socio-demographic data: patient anonymisation code, age, sex, health centre, area, health district, PIS state (active/inactive) and pharmacy status (with or without co-payment). Usage data needed for the CRG grouper were: number of contacts in primary health care, number of hospital admissions, and days in hospital per admission (main diagnosis, coded according to ICD-9CM). CRG data: CRG Base, ACRG1, ACRG2, ACRG3 (Table 1). Pharmaceutical cost data: cost of medicines according to the invoicing nomenclature of the Ministry for Health, Social Policies and Equality. These costs refer to the pharmaceutical expenditure in primary health care centres, which means the total cost is not included for health statuses 8 and 9 , given that the majority of these medicines are provided by the hospitals.

\section{Data sources}

Data for the study was obtained from the electronic health record for primary health care (SIA) and the Minimum Data Set (MDS) of hospitals. Data for primary health care pharmaceutical expenditure was obtained from the prescription module of the Pharmaceutical Provision Manager, GAIA. The full amount of each prescription expended during the study period was accounted for.

\section{CRG calculation}

To obtain the CRG we used $3 \mathrm{M}^{\mathrm{m}}$ Clinical Risk Grouping Software v.1.4. CRGs capture the resource utilization of all inpatient and ambulatory encounters. The groups identify individuals with multiple chronic co-morbid conditions and explicitly specify the severity of illness for each individual. The CRG system maps each diagnosis to one of 1,079 CRG groups that are similar in terms of relative severity, persistence, or recurrence, and health care resource expectations. CRGs, at the discretion of the user, can then be aggregated in order to reduce the number of groups. There are three tiers of aggregation. These are identified as ACRG1, ACRG2, and ACRG3 (Table 1). Each one progressively reduces the number of groups while maintaining, albeit with some adjustment, severity leveling. In the designed models we use 8 dummy variables - one for each core health status - plus 6 dummy variables for severity levels.

\section{Statistical analysis}

With the data for 2012, concurrent regression models were made using the total pharmaceutical expenditure by patient and year $(C)$ as dependent variable. As $C$ was not normally distributed, $\mathrm{C}$ is $\ln$-transformed as a better approach to its normal distribution [37].

As 420,000 patients $(8 \%)$ had cost 0 , which results in ln -inf, the final dependent variable was considered to be $C+1$, resulting in all cost values $<1$ having a positive $\mathrm{Ln}$ value. Prediction from these models must then be retransformed by subtracting -1 , to obtain estimates on the original scale.

Six models were made using the 2012 data, combining the following independent variables in each model:

(i) age and sex (1 male and 0 female);

(ii)age, sex, and 8 CRG core health statuses;

(iii) 8 CRG core health statuses alone;

(iv) 8 CRG core health statuses, only for the paediatric cohort;

(v) 8 CRG core health statuses excluding paediatrics cohort;

(vi) 8 CRG core health statuses, 6 severity levels, age and sex, excluding paediatric population.

In all models except (i), the healthy group (Health Status 1) was the control variable necessary in the regression model. Models (i), (ii) and (vi) were designed to observe if there is any difference between age and sex groups.

The models were estimated by means of ordinary least squares (OLS). The goodness of fit was determined through the corrected $R^{2}$ value and the F Snedecor, mean squared error, and for each of $\beta$ coefficients t-Student values were obtained to determine the level of significance. The assumptions of normality, homoscedasticity and linearity were considered. Split analysis validation to avoid overfitting was carried out. We used a random sample of $70 \%$ of the study subjects for model development and $30 \%$ for model validation.

The weight of each health status according to the pharmaceutical expenditure for this status was obtained by retransforming the predicted $\ln$ expenditures back into nominal using the smearing estimate provided by Duan (1983) [38]. With this nonparametric retransformation the 
Table 1 Population (N), annual pharmaceutical expenditure in Euros and age by CRG core health status and severity level (ACRG3) 2012

\begin{tabular}{l} 
ACGR3 \\
\hline 1. Healthy \\
10 Healthy \\
11 Healthy Non-User \\
12 Delivery without Other Significant IIIness \\
14 Pregnancy without Other Significant IIIness \\
15 Evidence of Significant Chronic or Acute \\
Diagnosis without Other Significant IIIness
\end{tabular}

\section{History of significant acute disease}

20 History Of Significant Acute Disease

22 Delivery with History of Significant Acute IIIness

24 Pregnancy with History of Significant Acute Illness

25 Evidence of Significant Chronic or Acute

Diagnosis with History of Significant Acute Illness

\section{Single minor chronic disease}

193,19

$4.15 \%$

15,875

$0.34 \%$

$7,108 \quad 0.15 \%$

44,836

$0.96 \%$

95.96

209.51

64.70

166.72

$1,853,851$

$3,325,971$

33.23

19.65

$$
459,888
$$

33.87

10.84

$7,475,058$

31.83

5.99

38.06

21.98

31 Single Minor Chronic Disease Level - 1

32 Single Minor Chronic Disease Level - 2

\section{Minor chronic disease in multiple Organ Systems \\ 41 Minor Chronic Disease In Multiple Organ Systems Level - 1 \\ 42 Minor Chronic Disease In Multiple Organ Systems Level - 2 \\ 43 Minor Chronic Disease In Multiple Organ Systems Level - 3 \\ 44 Minor Chronic Disease In Multiple Organ Systems Level - 4}

\section{Single dominant or moderate chronic disease}

51 Single Dominant Or Moderate Chronic Disease Level - 1

52 Single Dominant Or Moderate Chronic Disease Level - 2

53 Single Dominant Or Moderate Chronic Disease Level - 3

54 Single Dominant Or Moderate Chronic Disease Level - 4

55 Single Dominant Or Moderate Chronic Disease Level - 5

56 Single Dominant Or Moderate Chronic Disease Level - 6

\section{Chronic disease in $\mathbf{2}$ or more Organ Systems}

61 Significant Chronic Disease In Multiple Organ Systems Level - 1

62 Significant Chronic Disease In Multiple Organ Systems Level - 2

63 Significant Chronic Disease In Multiple Organ Systems Level - 3

\section{3,148}

41,173

90,903

25,3

34,801

5,204

$8.66 \%$

$0.88 \%$

190.25

258.48

$1.95 \%$

339.85

$0.54 \%$

515.28

520.02

704.89

$0.75 \%$

$0.11 \%$

704.89

64 Significant Chronic Disease In Multiple Organ Systems Level - 4

65 Significant Chronic Disease In Multiple Organ Systems Level - 5

66 Significant Chronic Disease In Multiple Organ Systems Level - 6

\section{Dominant Chronic Disease in 3 or more Organ Systems}

72 Dominant Chronic Disease In Three Or More Organ Systems Level - $2 \quad$ 5,913

73 Dominant Chronic Disease In Three Or More Organ Systems Level - $3 \quad$ 12,577

74 Dominant Chronic Disease In Three Or More Organ Systems Level - $4 \quad$ 3,587

75 Dominant Chronic Disease In Three Or More Organ Systems Level - 5

76 Dominant Chronic Disease In Three Or More Organ Systems Level - 6
217,363

484,232

135,731

39,795

5,13

9,556

761

93,125

62,212

40,647

\section{9,282}

2,259

$10.40 \%$

528.68

739.94

1108.05

1061.65

1348.04

1961.34

994.26

1362.09

1567.73

1835.01

2074.03

2087.73

$0.05 \%$

(2087.73

$0.15 \%$

$0.13 \%$

$0.27 \%$

$0.08 \%$

2,694

$0.06 \%$

1,076
1861.56

2159.61

2420.64

2677.64

2784.93

2528.73

\section{$76,698,907$}

$10,642,397$

30,893,385

130,366

$18,097,216$

$3,668,248$

$256,003,774$

$100,432,796$

$44,094,850$

$5,449,449$

$12,881,870$

$1,492,580$

$216,115,336$

$126,844,631$

$97,531,619$

$74,587,651$

$39,991,446$

$4,716,182$

$13,406,955$

$12,769,774$

$30,444,389$

$9,604,695$

$7,502,601$

$2,720,913$
45.58

43.19

18.58

19.23

55.72

15.69

61.58

13.52

57.91

15.38

14.99

59.07

54.76

21.09

54.37

22.66

59.30

19.73

21.39

66.70

17.46

18.79

51.56

15.42

66.93

69.14

14.57

70.90

13.95

72.87

13.26

75.06

13.02

13.40

75.24

10.35

10.54

10.33

9.95

10.08

10.06 
Table 1 Population ( $N$ ), annual pharmaceutical expenditure in Euros and age by CRG core health status and severity level (ACRG3) 2012 (Continued)

\begin{tabular}{|c|c|c|c|c|c|c|}
\hline ACGR3 & $\mathbf{N}$ & $\% \mathrm{~N}$ & $\begin{array}{c}\text { Average } \\
\text { expenditure }\end{array}$ & $\begin{array}{c}\text { Total } \\
\text { expenditure }\end{array}$ & $\begin{array}{c}\text { Average } \\
\text { age }\end{array}$ & $\begin{array}{l}\text { St. Dv. } \\
\text { age }\end{array}$ \\
\hline \multicolumn{7}{|l|}{ 8. Dominant and Metastatic Malignancies } \\
\hline 81 Dominant, Metastatic, And Complicated Malignancies Level - 1 & 1,677 & $0.04 \%$ & 800.04 & $1,341,667$ & 61.41 & 16.28 \\
\hline 82 Dominant, Metastatic, And Complicated Malignancies Level - 2 & 5,692 & $0.12 \%$ & 1223.61 & $6,964,788$ & 62.59 & 16.67 \\
\hline 83 Dominant, Metastatic, And Complicated Malignancies Level - 3 & 6,419 & $0.14 \%$ & 1649.05 & $10,585,252$ & 66.99 & 14.72 \\
\hline 84 Dominant, Metastatic, And Complicated Malignancies Level - 4 & 4,878 & $0.10 \%$ & 2021.68 & $9,861,755$ & 69.61 & 13.66 \\
\hline 85 Dominant, Metastatic, And Complicated Malignancies Level - 5 & 1,389 & $0.03 \%$ & 2131.74 & $2,960,987$ & 70.86 & 12.19 \\
\hline \multicolumn{7}{|l|}{ 9. Catastrophic conditions } \\
\hline 91 Catastrophic Conditions Level - 1 & 1,895 & $0.04 \%$ & 1632.93 & $3,094,402$ & 44.83 & 22.15 \\
\hline 92 Catastrophic Conditions Level - 2 & 3,647 & $0.08 \%$ & 1164.40 & $4,246,567$ & 46.30 & 16.97 \\
\hline 93 Catastrophic Conditions Level - 3 & 1,857 & $0.04 \%$ & 1944.29 & $3,610,547$ & 53.82 & 19.86 \\
\hline 94 Catastrophic Conditions Level - 4 & 2,02 & $0.04 \%$ & 1949.96 & 393,892 & 52.68 & 16.77 \\
\hline 95 Catastrophic Conditions Level - 5 & 976 & $0.02 \%$ & 2244.09 & $2,190,232$ & 63.49 & 16.67 \\
\hline 96 Catastrophic Conditions Level - 6 & 515 & $0.01 \%$ & 2368.46 & $1,219,757$ & 65.04 & 16.37 \\
\hline Total & $4,654,362$ & $100 \%$ & 298.71 & $1,301,898,793$ & 41.32 & 23.07 \\
\hline
\end{tabular}

homoscedastic error is corrected. Thus, the expression for this smearing estimate is:

$$
\begin{aligned}
E(C) & =E\left(e^{\left(x_{i} \beta\right) \varepsilon}\right) \\
& =\frac{1}{n} \sum_{i=1}^{n}\left(e^{\left(x_{i} \beta\right)+\varepsilon_{1}}\right) \\
& =\left(e^{\left(x_{i} \beta\right)}\right)\left(\frac{1}{n} \sum_{i=1}^{n}\left(e^{\varepsilon_{1}}\right)\right)=\left(e^{\left(x_{i} \beta\right)}\right) \gamma
\end{aligned}
$$

Where:

$\varepsilon=$ the residual errors.

$\mathrm{n}=$ number of observations.

With model iii selected to predict the cost, we established a case mix (CM) system based on the weights of each of the health statuses. Thus, it is possible to calculate the $\mathrm{CM}$ for the region and each health district and compare the allocated budget with real expenditure.

The equation for $C M_{j}$ calculation for each health district $\mathrm{j}$ is:

$$
C M_{j}=\frac{\sum_{i=1}^{9} N_{i j} W_{i}}{\sum_{i=1}^{9} N_{i j}}
$$

Where,

$N_{i j}=$ Number of population of group $i$ in the health district $j$.

$W_{i}=$ Weight of each $i$ core health status group.
The process used for obtaining a predictive budget by health district was the following: Firstly, the weights were calculated for 2012 using the regression model with real data to establish the relative consumption for each CRG. Through the expression (2) the CM is calculated. The Health Authority then established an overall budget for pharmaceutical expenditure for 2013, partly by taking into account the prior year's expenditure. Applying the weights, we calculated the number of adjusted patients, and divided the overall budget by this number, obtaining the standard price of an adjusted patient. This allows us to give a budget to each doctor or district according to the number of adjusted patients they have.

The model weights are recalibrated annually to introduce possible changes relating to health status, price changes and clinical practice. A cap is established, however, for maximum target budget. That is, a cost per patient adjusted by morbidity is set each year which is used to establish the budget.

\section{Results}

Patient stratification and pharmaceutical expenditure

Table 1 shows the number of patients, classified into each of the nine CRG core health statuses, percentage of patients and the average cost for the year 2012. In the graph for this data (Figure 1) it can be clearly seen how each strata of the population is related to the pharmaceutical expenditure. Health Status 6 (chronic disease in 2 or more organ systems) represents $48 \%$ of total primary 

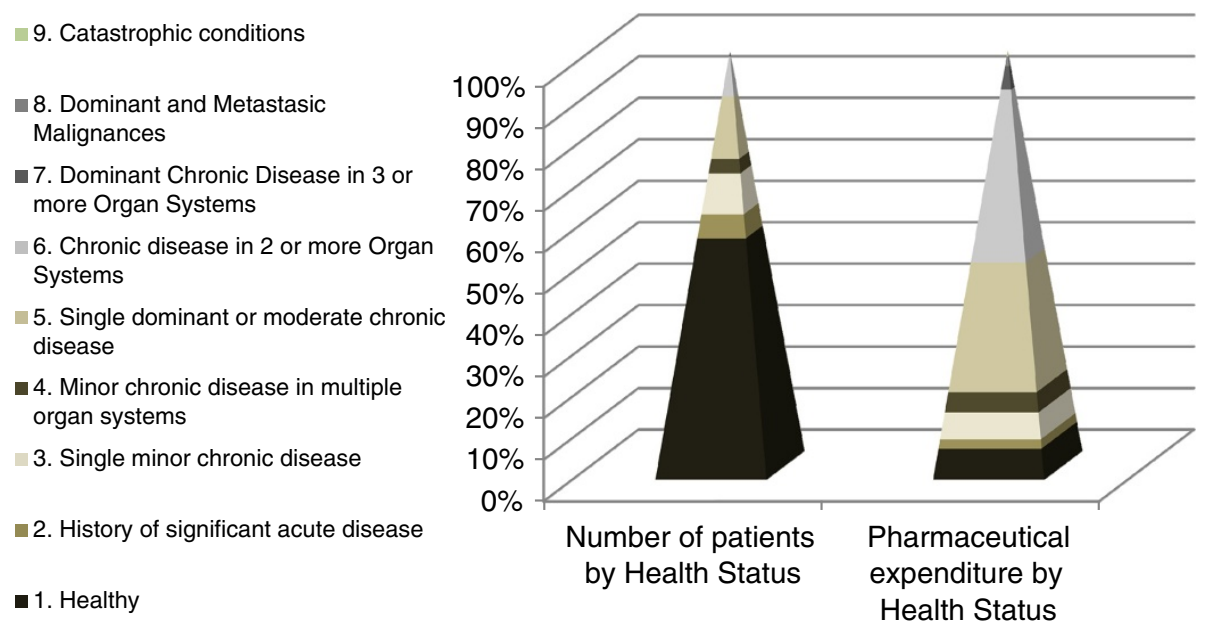

Figure 1 Stratification of patients by core health status and pharmaceutical expenditure in 2012. Shows a graph for the number of patients, classified into each of the nine CRG core health statuses, and the average cost in this period. In the graph for this data it can be clearly seen how each strata of the population is related to the pharmaceutical expenditure.

health care pharmaceutical expenditure despite only representing $11 \%$ of population.

Health status 5 (single dominant or moderate chronic disease) represents $26.4 \%$ of total primary health care pharmaceutical expenditure while only representing $15.1 \%$ of population. These two statuses together account $74.4 \%$ of total expenditure (Figure 1).

\section{Regression models}

In Table 2 we show the model coefficients and other statistics. Of the proposed models, model (vi) achieved the best fit, with an $\mathrm{R}^{2}$ of $60.3 \%$.

Furthermore, within the Spanish health system it is important to analyse the pharmaceutical expenditure for patients under 14, as these patients are attended by paediatricians in primary health care. Applying the CRG model (iv) to this cohort, we found a very low level of explanation, $15.8 \%$. Therefore a special predictive model must be developed for these patients.

In spite of models (ii), (v) and (vi) being better, we have taken the coefficients from model (iii), the $\mathrm{R}^{2}$ of which is $55 \%$ for reasons of operational and practical use and understanding by clinical users.

For the CM system implemented, relative weights were established by retransforming the coefficient for each health state through the smearing estimator and adding the value of 1 as presented in Table 3. The result of the smearing estimator $(\gamma)$, the mean of the anti-ln of the residuals, was 1.693 (expression 1).

It should be noted that for groups 8 and 9 we obtained lower weights than given by the original CRG. This is due to patients in these groups principally using hospital dispensaries, while our study drew data from primary health care only. These patients suffer from malignancies and catastrophic diseases such as renal failure or organ transplants.

\section{Analysis by health district}

Figure 2 shows the number of patients assigned to each health district, grouped in health statuses. The line represents the CM in the health departments, calculated as the summation of equivalent patients divided by real patients in each health district, expression (2).

Figure 3 shows the relation between predicted expenditure according to $\mathrm{CM}$ and real pharmaceutical expenditure in primary care for each health district. 13 health districts have spent less than was estimated by the proposed model considering the health status of patients assigned to them, and 11 have incurred higher costs than predicted. This means that with the same equivalent patients, some departments generate higher outpatient pharmaceutical spending than others and some health departments are managing pharmaceutical spending better than others (Table 4).

\section{Discussion}

The study results show the basis for a pharmaceutical management model designed to improve efficiency in the use of medicines and allocation of budgets. The main innovation is the linking of pharmaceutical expenditure to patient morbidity, a factor not introduced until now in the majority of European health systems.

Discussion points may be centred around three aspects: the reliability of the classification system, the predictive capacity of the developed model, and practical utility.

The reliability of CRGs with respect to correct patient stratification depends on the appropriate inclusion of 
Table 2 Results of different predictive models for pharmaceutical expenditure per year and patient (C) in Euros 2012

\begin{tabular}{|c|c|c|c|c|c|c|}
\hline & $\begin{array}{c}\text { Model i } \\
\text { age \& sex }\end{array}$ & $\begin{array}{c}\text { Model ii } \\
\text { CRG core } \\
\text { health status, } \\
\text { age \& sex }\end{array}$ & $\begin{array}{c}\text { Model iii } \\
\text { CRG core } \\
\text { health status }\end{array}$ & $\begin{array}{c}\text { Model iv } \\
\text { CRG core } \\
\text { health status }\end{array}$ & $\begin{array}{c}\text { Model v } \\
\text { CRG core } \\
\text { health status }\end{array}$ & $\begin{array}{c}\text { Model vi } \\
\text { CRG core health } \\
\text { status, severity } \\
\text { level, age \& sex }\end{array}$ \\
\hline Variables & Total population & Total population & Total population & Under or equal 14 & 14 PLUS & 14 PLUS \\
\hline Constant & 1.159 & 1.391 & 1.736 & 1.865 & 1.697 & .906 \\
\hline Age & .057 & .016 & & & & .026 \\
\hline Sex & -.461 & -.324 & & & & -.388 \\
\hline Health status 2 & & 1.751 & 1.816 & 1.262 & 1.955 & 1.873 \\
\hline Health status 3 & & 2.179 & 2.440 & 1.548 & 2.537 & 2.214 \\
\hline Health status 4 & & 3.201 & 3.691 & 2.134 & 3.743 & 2.951 \\
\hline Health status 5 & & 3.399 & 3.799 & 2.119 & 3.954 & 3.291 \\
\hline Health status 6 & & 4.352 & 4.992 & 3.120 & 5.048 & 3.946 \\
\hline Health status 7 & & 5.055 & 5.760 & 3.920 & 5.801 & 4.400 \\
\hline Health status 8 & & 4.325 & 4.870 & 1.891 & 4.946 & 3.713 \\
\hline Health status 9 & & 4.217 & 4.493 & 3.129 & 4.608 & 3.785 \\
\hline Severity level 2 & & & & & & .406 \\
\hline Severity level 3 & & & & & & .613 \\
\hline Severity level 4 & & & & & & .701 \\
\hline Severity level 5 & & & & & & .823 \\
\hline Severity level 6 & & & & & & .878 \\
\hline $\mathrm{F}$ & 883600.05 & 613728.44 & 711221.29 & 17380.11 & 650280.64 & 396142.59 \\
\hline N & $4,654,362$ & $4,654,362$ & $4,654,362$ & 739,525 & $3,914,837$ & $3,914,837$ \\
\hline$R^{2}$ & 0.275 & 0.569 & 0.550 & 0.158 & 0.571 & 0.603 \\
\hline
\end{tabular}

the diagnostics in the Electronic Health Record (EHR). One of the indicators for evaluating this is the percentage of healthy patients, both users and non-users. The results presented here have greatly improved with respect to stratifications undertaken in the trial period and those presented by other authors. The deficiencies in the initial diagnostics code gave this group as being $60 \%$ of the population, whereas with correct coding the value is $52 \%$, representing the real proportion (34\% healthy users and $16 \%$ non-users). This indicates a substantial improvement in the codification. Other authors, using data from 2008 , give this status to $70 \%$ of the population [30].

The proposed model uses population stratification into risk groups based on CRGs, but develops its own weights for CRG core health statuses. If we compare the predictive capacity of this model with others described in the bibliography that use other patient classification systems, we see that it reaches, at minimum, the same level of explanation

Table 3 Calculation for weights by CRG core health status from model 2012

\begin{tabular}{lcc}
\hline Core health status & Ln (C+ 1) (a) & Expenditure C (b) \\
\hline 1. Healthy & 1.736 & 8.607 \\
2. History of significant acute disease & 3.552 & 58.068 \\
3. Single minor chronic disease & 4.176 & 109.242 \\
4. Minor chronic disease in multiple organ systems & 5.75 & 384.212 \\
5. Single dominant or moderate chronic disease & 5.427 & 42.69 \\
6. Chronic disease in 2 or more Organ Systems & 5.535 & 44.64 \\
7. Dominant Chronic Disease in 3 or more Organ Systems & 6.728 & 1413.267 \\
8. Dominant and Metastasic Malignances & 7.496 & 3048.575 \\
9. Catastrophic conditions & 6.606 & 1250.432 \\
\hline
\end{tabular}

(a) $=\operatorname{Ln}(C+1)$.

(b) $=\left(1.693 \mathrm{e}^{\mathrm{a}}\right)-1$.

(c) $=b_{i} / b_{1}$. 


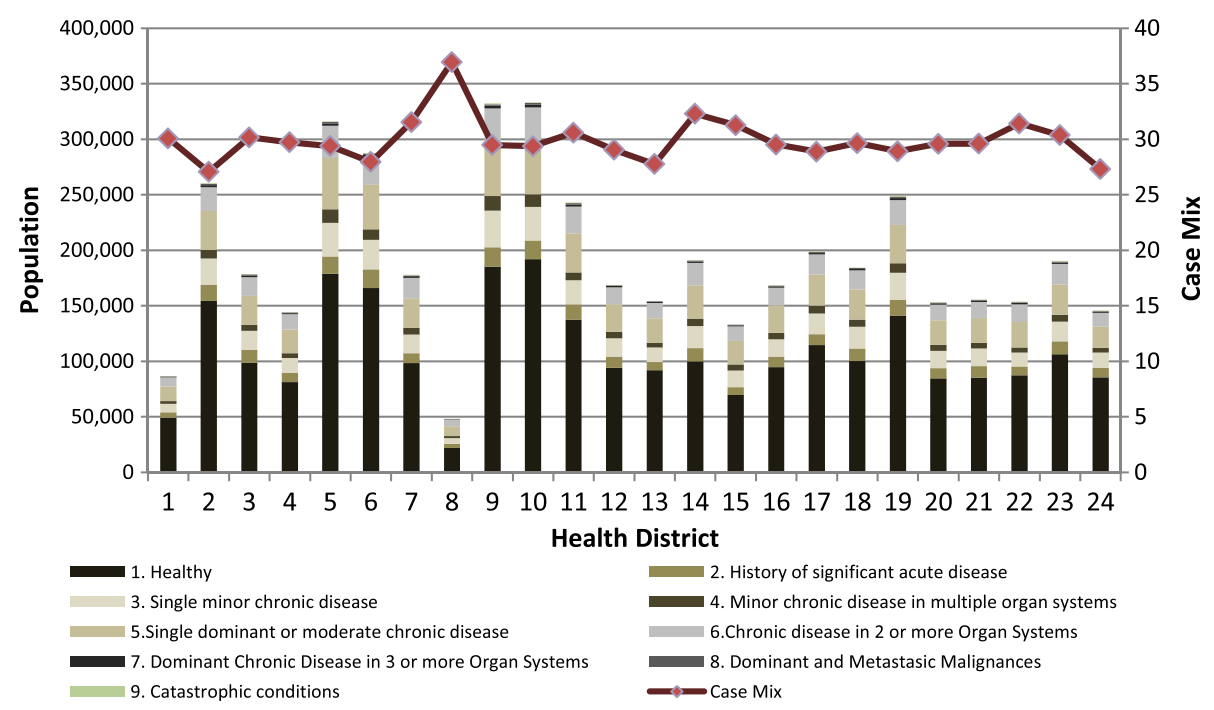

Figure 2 CRG core health status by health district and case mix 2012. Shows a stacked column chart, comparing the contribution of each value to a total across categories of CRGs core health statuses for each health districts. The $x$ axis of the chart shows the health districts compared and the $y$ axis represent a double scale with the case mix on the right and the $n^{\circ}$ of patient grouped by CRG core health status on the left.

in terms of $\mathrm{R}^{2}$ and $\mathrm{t}$-student statistics. Thus, the models based on patient classification using ATC [36] achieve an $\mathrm{R}^{2}$ of $57 \%$, the models based on ACG [23] 35.4\%, and those that use DxRx-PMs [39] 42.6\%.

As the goal of our model is to assign predictive budgets with an objective level of expenditure for the health districts and primary health care physicians, it should be noted that the general model does not serve for the population of under-14s attended by paediatricians. As such, this is one of the weaknesses of a CRG based model. This also occurs in the ACG system, as indicated by Aguado et al. [23], who note that in children there is greater variability among physicians and centres not related to case-mix.

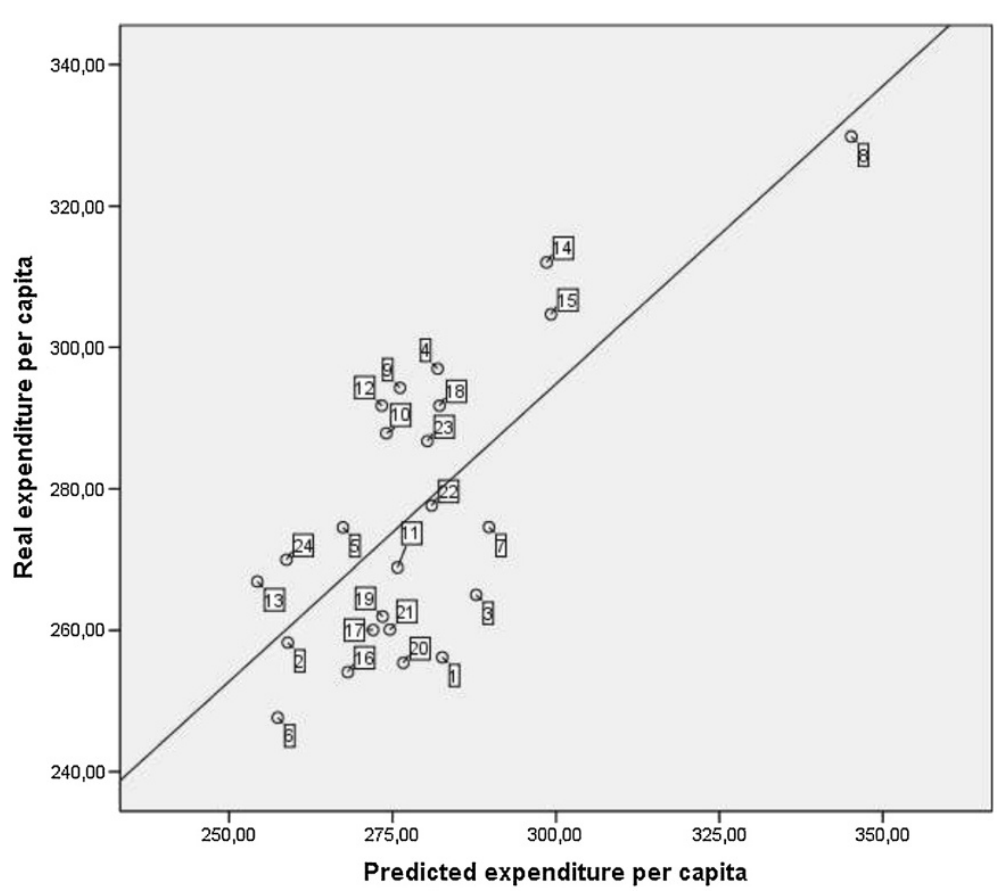

Figure 3 Pharmaceutical expenditure real and predicted by health district 2013. Shows a scatter plot to display values for real (y axis) and predicted ( $\mathrm{x}$ axis) pharmaceutical expenditure of each heath district. 
Table 4 Real and predicted pharmaceutical expenditure and case mix adjusted by health district in 2013

\begin{tabular}{|c|c|c|c|c|c|c|c|}
\hline Health district & Case mix (1) & Real C (2) & Predicted C (3) & Population. N (4) & $\begin{array}{l}\text { Average real } \\
\mathrm{C}(5)=(2) /(4)\end{array}$ & $\begin{array}{l}\text { Average predicted } \\
\mathrm{C}(6)=(3) /(4)\end{array}$ & $\begin{array}{l}\text { Differences } \\
(7)=(5)-(6) \\
\end{array}$ \\
\hline 1 & 35.29 & $22,404,536.70$ & $24,714,441.39$ & 87,448 & 256.20 & 282.62 & -26.41 \\
\hline 2 & 32.34 & $68,608,549.95$ & $68,793,348.13$ & 265,636 & 258.28 & 258.98 & -0.70 \\
\hline 3 & 35.94 & $47,720,043.15$ & $51,816,313.29$ & 180,051 & 265.04 & 287.79 & -22.75 \\
\hline 4 & 35.20 & $43,430,451.48$ & $41,221,848.93$ & 146,219 & 297.02 & 281.92 & 15.10 \\
\hline 5 & 33.39 & $88,177,744.42$ & $85,893,722.31$ & 321,192 & 274.53 & 267.42 & 7.11 \\
\hline 6 & 32.15 & $72,489,772.23$ & $75,357,459.28$ & 292,715 & 247.65 & 257.44 & -9.80 \\
\hline 7 & 36.18 & $49,825,584.93$ & $52,580,973.57$ & 181,468 & 274.57 & 289.75 & -15.18 \\
\hline 8 & 43.10 & $15,989,816.02$ & $16,733,570.96$ & 48,479 & 329.83 & 345.17 & -15.34 \\
\hline 9 & 34.48 & $99,701,853.24$ & $93,549,589.70$ & 338,770 & 294.31 & 276.14 & 18.16 \\
\hline 10 & 34.22 & $97,918,781.79$ & $93,218,916.90$ & 340,151 & 287.87 & 274.05 & 13.82 \\
\hline 11 & 34.43 & $66,559,137.30$ & $68,259,770.67$ & 247,529 & 268.89 & 275.76 & -6.87 \\
\hline 12 & 34.13 & $49,736,535.24$ & $46,595,511.68$ & 170,456 & 291.79 & 273.36 & 18.43 \\
\hline 13 & 31.76 & $41,575,756.05$ & $39,612,929.41$ & 155,755 & 266.93 & 254.33 & 12.60 \\
\hline 14 & 37.28 & $60,142,256.18$ & $57,547,721.39$ & 192,759 & 312.01 & 298.55 & 13.46 \\
\hline 15 & 37.36 & $40,973,176.21$ & $40,243,795.62$ & 134,490 & 304.66 & 299.23 & 5.42 \\
\hline 16 & 33.48 & $43,043,816.92$ & $45,423,640.85$ & 169,389 & 254.11 & 268.16 & -14.05 \\
\hline 17 & 33.97 & $52,476,085.67$ & $54,889,413.61$ & 201,780 & 260.07 & 272.03 & -11.96 \\
\hline 18 & 35.24 & $54,265,489.06$ & $52,482,585.31$ & 185,984 & 291.78 & 282.19 & 9.59 \\
\hline 19 & 34.15 & $66,260,672.07$ & $69,172,538.68$ & 252,932 & 261.97 & 273.48 & -11.51 \\
\hline 20 & 34.54 & $39,467,859.22$ & $42,750,213.31$ & 154,533 & 255.40 & 276.64 & -21.24 \\
\hline 21 & 34.29 & $41,080,531.21$ & $43,366,934.60$ & 157,932 & 260.12 & 274.59 & -14.48 \\
\hline 22 & 35.09 & $44,150,450.69$ & $44,686,006.13$ & 159,031 & 277.62 & 280.99 & -3.37 \\
\hline 23 & 35.01 & $55,746,290.13$ & $54,498,692.53$ & 194,401 & 286.76 & 280.34 & 6.42 \\
\hline 24 & 32.31 & $40,153,602.94$ & $38,488,854.55$ & 148,732 & 269.97 & 258.78 & 11.19 \\
\hline Total & 34.38 & $1,301,898,792.80$ & $1,301,898,792.80$ & $4,727,832$ & 275.37 & 275.37 & 0.00 \\
\hline
\end{tabular}

(1) District case mix (CM).

(2) Annual real cost.

(3) Predictive expenditure health district $=$ real expenditure ${ }_{v c} C M_{\text {health district }} N_{\text {health district }} / C M_{c v} N_{v c}$

(4) Health district total population.

For a target consumption based on forecasts by the model, there are two other variables to consider in pharmaceutical expenditure in budgetary adjustments: the cost of the medicines and the goals of the adjustment. Over recent years we have effectively seen drops of around $7 \%$ in the price of medicines, driven by the increase in the consumption of generics and the reduction in prices from the Ministry for Health, Social Policies and Equality. During the last three years there has been a decrease every month in the prices set by the Spanish Agency for Medicines (Agencia Española de Medicamentos).

The other factor is the adjustment of pharmaceutical expenditure made by the health authorities via the protocols of rational use that prevent multiple medication of a patient and the use of medicines not based on evidence, especially in chronic pathologies such as hypercholesterolemia or osteoporosis. As such, in establishing expenditure goals by district and doctor from the specific experience from the VC for 2013, the forecast expenditure of the model decreases by $15 \%$.

We observed the need for advanced and efficient IT development as a condition for the introduction of this system. Firstly, for the stratification of patients using the CRG system and then a further programme to communicate the classifications and predictions to the health districts and health workers. The IT system developed allows us to know the chronic diseases and co-morbidity of the patients included in each health status. This is of the greatest use when managing patients in programmes for the most prevalent chronic diseases. The system is linked to the EHR, making it possible to know all the diagnoses, treatments, hospital stays, etc.

\section{Conclusions}

The developed model based on CRGs can be of great use in managing the pharmaceutical spending in integrated 
health services such as the National Health Service (NHS). In future development hospital pharmaceutical expenditure must be included to better explain the weights of statuses 8 and 9 .

The predictive power of the developed model is similar to other models based on diagnostics, validating its use in managing primary health care pharmaceutical expenditure.

The general case-mix model is not applicable for establishing expenditure goals for paediatrics, as the CRG classification system is not valid for isolated patients of under 14 years of age.

The predictive models must consider adjustments which include variations in the price of medicines and rationalisation measures in pharmaceutical expenditure, so as to produce incentive-based targets.

\section{Competing interests}

The authors declare that they have no competing interests.

\section{Authors' contributions}

DVA designed the study and drafted the manuscript. RU and JLTM applied the CRG software and carried out the first calculations of the results. NGO rechecked and revised the statistical analysis with assistance from CSM. LBP compiled the prescription cost invoiced to the health system and prepared the databases before being analyzed. All authors read and approved the final manuscript.

\section{Authors' information}

David Vivas-Consuelo (DVC) and Natividad Guadalajara-Olmeda (NGO) are PhD Professors in the Research Centre for Health Economics and Management at Universitat Politècnica de València (Spain) and Carla Sancho-Mestre is a PhD candidate of the same university. José Luis Trillo-Mata (JLTM) and Ruth Usó-Talamantes (RUT) are Director and Deputy Director of the General Direction of Pharmacy and Pharmaceutical Products in the Valencian Health Departament (Spain). Laia Buigues-Pastor (LBP) works as an economist at the Pharmacoeconomics office in the same institution.

\section{Acknowledgments}

This study was financed by a grant from the Fondo de Investigaciones de la Seguridad Social Instituto de Salud Carlos III, the Spanish Ministry of Health (FIS PI12/0037). The authors would like to thank members (Juan Bru and Inma Sauri) of the Pharmacoeconomics Office of the Valencian Health Department. The opinions expressed in this paper are those of the authors and do not necessary reflect those of the afore-named. Any errors are the authors' responsibility. We would also like to thank John Wright for the English editing.

\section{Author details}

${ }^{1}$ Research Centre for Health Economics and Management, Universitat Politècnica de València, Edificio 7 J, Campus de Vera s/n, 46022 Valencia, Spain. ${ }^{2}$ Valencian Health Department (Conselleria de Sanitat), General Directorate of Pharmacy and Pharmaceutical Products, Valencia, Spain.

Received: 27 November 2013 Accepted: 16 September 2014 Published: 21 October 2014

\section{References}

1. Hux JE, Naylor CD: Drug prices and third party payment: do they influence medication selection? Pharmacoecon 1994, 5(4):343-350.

2. Sicras-Mainar A, Serrat-Tarres J, Navarro-Artieda R, Llopart-Lopez J: [Prospects of adjusted clinical groups (ACG's) in capitated payment risk adjustment]. Rev Esp Salud Publica 2006, 80(1):55-65.

3. Mossey JM, Roos LL: Using insurance claims to measure health-status - the illness scale. J Chronic Dis 1987, 40:S41-S50.
4. Newhouse JP, Manning WG, Keeler EB, Sloss EM: Adjusting capitation rates using objective health measures and prior utilization. Health Care Financ Rev 1989, 10(3):41-54.

5. Ash A, Porell F, Gruenberg L, Sawitz E, Beiser A: Adjusting Medicare capitation payments using prior hospitalization data. Health Care Financ Rev 1989, 10(4):17-29.

6. Ellis RP, Pope GC, lezzoni L, Ayanian JZ, Bates DW, Burstin H, Ash AS: Diagnosis-based risk adjustment for Medicare capitation payments. Health Care Financ Rev 1996, 17(3):101-128.

7. Pope GC, Kautter J, Ellis RP, Ash AS, Ayanian JZ, Lezzoni LI, Ingber MJ, Levy $J M$, Robst J: Risk adjustment of Medicare capitation payments using the CMS-HCC model. Health Care Financ Rev 2004, 25(4):119-141.

8. Starfield B, Weiner J, Mumford L, Steinwachs D: Ambulatory care groups: a categorization of diagnoses for research and management. Health Serv Res 1991, 26(1):53-74.

9. Weiner JP, Starfield BH, Steinwachs DM, Mumford LM: Development and application of a population-oriented measure of ambulatory care case-mix. Med Care 1991, 29(5):452-472.

10. Hughes JS, Averill RF, Eisenhandler J, Goldfield NI, Muldoon J, Neff JM, Gay JC: Clinical Risk Groups (CRGs): a classification system for risk-adjusted capitation-based payment and health care management. Med Care 2004, 42(1):81-90

11. Berlinguet M, Preyra C, Dean S: Comparing the Value of Three Main Diagnostic-Based Risk-Adjustment Systems (DBRAS). Ottawa, Ontario: Edited by Foundation CHSR; 2005

12. Von Korff M, Wagner EH, Saunders K: A chronic disease score from automated pharmacy data. J Clin Epidemiol 1992, 45(2):197-203.

13. Malone DC, Billups SJ, Valuck RJ, Carter BL: Development of a chronic disease indicator score using a Veterans Affairs Medical Center medication database. IMPROVE Investigators. J Clin Epidemiol 1999, 52(6):551-557

14. Clark DO, Von Korff M, Saunders K, Baluch WM, Simon GE: A chronic disease score with empirically derived weights. Med Care 1995, 33(8):783-795.

15. Lamers LM: Pharmacy costs groups: a risk-adjuster for capitation payments based on the use of prescribed drugs. Med Care 1999, 37(8):824-830.

16. Lamers LM: Health-based risk adjustment: is inpatient and outpatient diagnostic information sufficient? Inquiry 2001, 38(4):423-431.

17. Lamers LM, van Vliet RC: The Pharmacy-based Cost Group model: validating and adjusting the classification of medications for chronic conditions to the Dutch situation. Health Policy 2004, 68(1):113-121.

18. Lamers LM, Vliet RC: Health-based risk adjustment Improving the pharmacy-based cost group model to reduce gaming possibilities. Eur $\int$ Health Econ 2003, 4(2):107-114.

19. Johnson RE, Hornbrook MC, Nichols GA: Replicating the chronic disease score (CDS) from automated pharmacy data. J Clin Epidemiol 1994, 47(10):1191-1199.

20. Zhao Y, Ellis RP, Ash AS, Calabrese D, Ayanian JZ, Slaughter JP, Weyuker L, Bowen B: Measuring population health risks using inpatient diagnoses and outpatient pharmacy data. Health Serv Res 2001, 36(6 Pt 2):180-193.

21. Stam PJ, van Vliet RC, van de Ven WP: Diagnostic, pharmacy-based, and self-reported health measures in risk equalization models. Med Care 2010, 48(5):448-457.

22. Hanley GE, Morgan S, Reid RJ: Explaining prescription drug use and expenditures using the adjusted clinical groups case-mix system in the population of British Columbia, Canada. Can Med Care 2010, 48(5):402-408.

23. Aguado A, Guino E, Mukherjee B, Sicras A, Serrat J, Acedo M, Ferro JJ, Moreno $\mathrm{V}$ : Variability in prescription drug expenditures explained by adjusted clinical groups (ACG) case-mix: a cross-sectional study of patient electronic records in primary care. BMC Health Serv Res 2008, 8(4):11.

24. Garcia-Goni M, Ibern P: Predictability of drug expenditures: An application using morbidity data. Health Econ 2008, 17(1):119-126.

25. Garcia-Goni M, Ibern P, Inoriza JM: Hybrid risk adjustment for pharmaceutical benefits. Eur J Health Econ 2009, 10(3):299-308.

26. Vivas-Consuelo D, Uso-Talamantes R, Trillo-Mata JL, Caballer-Tarazona M, Barrachina-Martinez I, Buigues-Pastor L: Predictability of pharmaceutical spending in primary health services using Clinical Risk Groups. Health Policy 2014, 116(2-3):188-195.

27. Robst J, Levy JM, Ingber MJ: Diagnosis-based risk adjustment for medicare prescription drug plan payments. Health Care Financ Rev 2007, 28(4):15-30 
28. Zhao Y, Ash AS, Ellis RP, Ayanian JZ, Pope GC, Bowen B, Weyuker L: Predicting pharmacy costs and other medical costs using diagnoses and drug claims. Med Care 2005, 43(1):34-43.

29. Buchner F, Goepffarth D, Wasem J: The new risk adjustment formula in Germany: implementation and first experiences. Health Policy 2013 , 109(3):253-262

30. Inoriza JM, Coderch J, Carreras M, Vall-Llosera L, Garcia-Goni M, Lisbona JM, Ibern P: [Measurement of morbidity attended in an integrated health care organization]. Gac Sanit 2009, 23(1):29-37.

31. Orueta JF, Mateos Del Pino M, Barrio Beraza I, Nuno Solinis R, Cuadrado Zubizarreta M, Sola Sarabia C: [Stratification of the population in the Basque Country: results in the first year of implementation.]. Aten Primaria 2012, 45(1):54-60.

32. Sicras-Mainar A, Navarro-Artieda R: [Validating the Adjusted Clinical Groups [ACG] case-mix system in a Spanish population setting: a multicenter study]. Gac Sanit 2009, 23(3):228-231.

33. Omar RZ, O'Sullivan C, Petersen I, Islam A, Majeed A: A model based on age, sex, and morbidity to explain variation in UK general practice prescribing: cohort study. BMJ 2008, 337:a238.

34. Caballer-Tarazona M, Buigues-Pastor L, Saurí- Ferrer I, Uso-Talamantes R, Trillo-Mata JL: [A standardized amount indicator by equivalent patient to control outpatient pharmaceutical expenditure, Spain]. Rev Esp Salud Publica 2011, 86:371-380.

35. De la Poza-Plaza E, Barrachina I, Trillo-Mata J, Uso-Talamantes R: Sistema de Prescripción y dispensación electrónica en la Agencia Valenciana de Salud. El Prof de la Inf 2011, 20:9.

36. Vivas D, Guadalajara N, Barrachina I, Trillo JL, Uso R, De-la-Poza E: Explaining primary healthcare pharmacy expenditure using classification of medications for chronic conditions. Health Policy 2011, 103(1):9-15.

37. Buntin MB, Zaslavsky AM: Too much ado about two-part models and transformation? Comparing methods of modeling Medicare expenditures. J Health Econ 2004, 23(3):525-542.

38. Duan N: Smearing estimate - a nonparametric retransformation method. J Am Stat Assoc 1983, 78(383):605-610.

39. Calderon-Larranaga A, Abrams C, Poblador-Plou B, Weiner JP, Prados-Torres A Applying diagnosis and pharmacy-based risk models to predict pharmacy use in Aragon, Spain: the impact of a local calibration. BMC Health Serv Res 2010, 10:22.

doi:10.1186/1472-6963-14-462

Cite this article as: Vivas-Consuelo et al:: Pharmaceutical cost management in an ambulatory setting using a risk adjustment tool. BMC Health Services Research 2014 14:462.

\section{Submit your next manuscript to BioMed Central and take full advantage of:}

- Convenient online submission

- Thorough peer review

- No space constraints or color figure charges

- Immediate publication on acceptance

- Inclusion in PubMed, CAS, Scopus and Google Scholar

- Research which is freely available for redistribution 